\title{
Intraoperative molecular analysis of sentinel lymph nodes following neoadjuvant chemotherapy in patients with clinical node negative breast cancer: An institutional study
}

\author{
DAVID PARADA ${ }^{1,2^{*}}$, KARLA B. PEÑA ${ }^{1,2^{*}}$, F. FRANCESC RIU ${ }^{1,2}$, \\ A. ESTHER AGUILAR ${ }^{3}$ and SEBASTIAN COHAN ${ }^{4}$ \\ ${ }^{1}$ Department of Pathology, University Hospital Sant Joan de Reus; \\ ${ }^{2}$ Pere Virgili Health Research Institute (IISPV), University Rovira i Virgill, E-43201 Tarragona; \\ Departments of ${ }^{3}$ Gynecology and ${ }^{4}$ Radiodiagnostics, University Hospital Sant Joan de Reus, E-43204 Tarragona, Spain
}

Received February 3, 2016; Accepted July 25, 2016

DOI: $10.3892 / \mathrm{mco} .2016 .1025$

\begin{abstract}
Sentinel lymph node biopsy (SLNB) is an accurate, safe method for determining the axillary lymph node status. However, insufficient evidence exists to support the recommendation of SLNB in patients who have had neoadjuvant chemotherapy (NAC) to downsize tumours and allow for breast conservation surgery. The present study aimed to use molecular approaches to evaluate the feasibility and accuracy of SLNB in patients treated with NAC prior to SLN mapping and surgery. A total of 50 consecutive patients with operable invasive breast carcinomas who had received prior NAC were assessed using the one-step nucleic acid amplification (OSNA) method. The rate of SLN identification was $100 \%$. The OSNA assay showed that 29 patients $(58 \%)$ were negative for SLN and 21 patients (42\%) were positive. In 19 of these 21 patients (90.48\%), the SLN was the only positive lymph node. No axillary lymph nodes metastases were observed in patients with isolated tumour cells or with micrometastases. The OSNA assay is a highly sensitive, specific and reproducible diagnostic technique that can be used to analyse SLNs following NAC. The total tumoral load may assist with predicting additional non-SLN metastases.
\end{abstract}

\section{Introduction}

Sentinel lymph node biopsy (SLNB), which is widely accepted as an accurate, safe method for diagnosing the axillary lymph node status of clinically node-negative breast cancer patients,

Correspondence to: Dr David Parada, Department of Pathology, University Hospital Sant Joan de Reus, University Rovira i Virgill, Avenida del Dr. Josep Laporte 1, Reus, E-43201 Tarragona, Spain E-mail:dparada@grupsagessa.com

*Contributed equally

Key words: sentinel node, neoadjuvant chemotherapy, one-step nucleic acid amplification, breast, cancer, molecular has replaced axillary lymph node dissection (1). However, insufficient evidence exists to support the recommendation of SLNB for certain pathologies, including locally advanced breast cancer (LABC). LABC, a heterogeneous group of operable and non-operable lesions at initial diagnosis, is often treated with neoadjuvant chemotherapy (NAC) as the standard of care. This treatment increases the rate of breast conservation and provides an opportunity to assess the tumour response to pharmacological agents $(2,3)$. Nonetheless, insufficient evidence exists to support the recommendation of SLNB in patients who have had NAC to downsize tumours and allow for breast conservation surgery (4).

The present study used molecular approaches to evaluate the feasibility and accuracy of SLNB in LABC patients treated with NAC prior to SLN mapping and surgery. The correlation of SLNB findings with the results of axillary lymphadenectomy was also assessed. The study population included patients with locally advanced infiltrating breast cancer at presentation. The SLNB results for these patients were compared to those previously reported for LABC patients who received NAC.

\section{Materials and methods}

Patients. The present study analysed 50 consecutive patients with operable invasive breast carcinomas who had received NAC between February 2011 and November 2015 at Sant Joan University Hospital (Reus, Spain). All patients underwent preoperative clinical assessment of lymph-node status by palpation and axillary ultrasound. The diagnostic criteria for locally advanced infiltrating breast cancer were a tumour size of at least $2 \mathrm{~cm}(\mathrm{~T}>2)$ and a negative axillary node (N0) status. The exclusion criterion was a CK19-negative status of tumours at pre-operative biopsy. The SLNs of the patients were assayed by one-step nucleic acid amplification (OSNA) to detect SLN metastasis. SLNs were identified in all of the patients (100\%). Clinicopathological data, including age, clinical tumour size, pathological tumour size, histological type, nuclear grade, tumour response to chemotherapy, oestrogen and progesterone receptor levels, HER2 status and Ki-67 nuclear expression [immunohistochemistry (IHC)-4] were collected. The cases 
were staged according to the American Joint Committee on Cancer Tumor-Nodes-Metastasis classification, $7^{\text {th }}$ edition (5). Patient characteristics are shown in Table I.

OSNA assay. The OSNA assay, which is based on the principles of reverse transcription loop-mediated isothermal amplification, was performed as previously described (6) After the fatty tissue had been removed, the SLN was weighed and whole SLN tissues were processed by the OSNA assay. The LN was assessed as OSNA - when the number of CK19 mRNA copies was $<2.5 \times 10^{2} / \mu 1$, OSNA + (micrometastases) when it was $2.5 \times 10^{2}-5.0 \times 10^{3}$ copies $/ \mu 1$ and OSNA ++ (macrometastases) when it was $>5.0 \times 10^{3}$ copies $/ \mu 1$. On occasion, the OSNA assay is inhibited by certain inhibitory materials, which leads to false-negative ( $<250$ copies $/ \mu 1)$ results, which may be changed into positive $(>250$ copies $/ \mu 1)$ by sample dilution $(1: 10)$. However, following dilution, the results are less reliable for quantitative assessment and were presented as +inhibition $(+\mathrm{I})$ [Isolated Tumour Cells (ITC)]. Standard statistics were used for analysis of patient data. $\mathrm{P}<0.05$ was considered to indicate a statistically significant difference.

Ethical considerations. The present study was approved by the Clinical Ethics Committee of the Sant Joan University Hospital (no. 14-02-27/2proj1).

\section{Results}

The clinical and pathological characteristics of 50 patients treated with NAC prior to SLNB are listed in Table I. The average age of the patients was 50 years, (range, 32-79 years). In 44 patients $(88.0 \%)$, the tumour was classes as no special type invasive carcinoma, according to the World Health Organization classification system, and in 6 patients $(12 \%)$ it was special type carcinoma. According to analysis using the IHC-4 system for classifying invasive carcinoma, luminal B was the most frequent type (26 patients, $52 \%$ ), followed by triple negative in 11 patients (22\%), HER2 in 7 patients (14\%) and luminal $\mathrm{A}$ in 6 patients (12\%). As for the pathological tumour response to chemotherapy, a partial response was achieved in 36 patients $(72 \%)$ and a complete response in 12 patients (24\%). Only 2 patients (4\%) exhibited no response to treatment (one luminal B and one triple negative) (Table II).

A total of 90 lymph nodes were obtained from the 50 patients and assessed using the OSNA assay, with an average of 2 SLN/patient (range, 1-4). In 29 patients (58\%), the ONSA assay was OSNA -. Of the remaining 21 patients (42\%) with positive SLN, 1 patient had ITC, 15 had micrometastases and 5 had macrometastases. In 19 (90.48\%) of these 21 patients, SLN were the only OSNA-positive lymph nodes. In 2 of the patients with macrometastases (9.72\%), SLN and more than one axillary lymph node were OSNA-positive. These 2 patients exhinited a partial response to chemotherapy. No axillary lymph node metastases were observed in any of the patients with ITC or with micrometastases.

\section{Discussion}

The SLNB technique is now widely used in numerous medical institutions worldwide and has become the standard of care
Table I. Patient and tumour characteristics.

\begin{tabular}{|c|c|c|}
\hline Characteristics & No. & $\%$ \\
\hline \multicolumn{3}{|l|}{ Age } \\
\hline$<50$ years & 26 & 52 \\
\hline$>50$ years & 24 & 48 \\
\hline \multicolumn{3}{|l|}{ Histological type } \\
\hline No special type & 44 & 88 \\
\hline Special type & 6 & 12 \\
\hline \multicolumn{3}{|l|}{ Nuclear grade } \\
\hline 1 & 0 & 0 \\
\hline 2 & 21 & 42 \\
\hline 3 & 29 & 58 \\
\hline \multicolumn{3}{|c|}{ Immunohistochemical-4 type } \\
\hline Luminal A & 6 & 12 \\
\hline Luminal B & 26 & 52 \\
\hline HER2 & 7 & 14 \\
\hline Triple negative & 11 & 22 \\
\hline \multicolumn{3}{|c|}{$\begin{array}{l}\text { Pathological T classification } \\
\text { [post-treatment (ypT)] }\end{array}$} \\
\hline pT0 & 12 & 24 \\
\hline pT1 & 27 & 54 \\
\hline pT2 & 7 & 14 \\
\hline pT3 & 4 & 8 \\
\hline \multicolumn{3}{|c|}{$\begin{array}{l}\text { Pathological response to } \\
\text { chemotherapy }\end{array}$} \\
\hline No response & 2 & 4 \\
\hline Partial & 36 & 72 \\
\hline Complete & 12 & 24 \\
\hline \multicolumn{3}{|c|}{ No. of removed sentinel nodes } \\
\hline 1 & 23 & 46 \\
\hline 2 & 16 & 32 \\
\hline 3 & 9 & 18 \\
\hline 4 & 2 & 4 \\
\hline
\end{tabular}

Table II. Response to chemotherapy according to IHC-4 type.

\begin{tabular}{lccr}
\hline & \multicolumn{3}{c}{ No. patients (\%) } \\
\cline { 2 - 4 } IHC-4 type & $\begin{array}{c}\text { No } \\
\text { response }\end{array}$ & $\begin{array}{c}\text { Partial } \\
\text { response }\end{array}$ & $\begin{array}{c}\text { Complete } \\
\text { response }\end{array}$ \\
\hline Luminal A & 0 & $5(10)$ & $1(2)$ \\
Luminal B & $1(2)$ & $21(42)$ & $4(8)$ \\
HER2 & 0 & $3(6)$ & $4(8)$ \\
Triple negative & $1(2)$ & $7(14)$ & $3(6)$ \\
\hline
\end{tabular}

IHC, immunohistochemistry.

to reduce upper limb morbidities commonly encountered following axillary lymph node dissection, including lymphoedema, shoulder stiffness and chronic pain $(7,8)$. One point 
of controversy is whether SLNB is useful in patients who have received prior chemotherapy. It has been suggested that primary chemotherapy can modify lymphatic drainage patterns within the axilla $(9,10)$ and that tumour shrinkage can distort lymphatics due to the creation of aberrant lymphatic drainage patterns (10). These two situations may affect the detection of SLNB. Single-institution studies have reported sensitivity rates of $72-100 \%$, with false-negative rates of $0-33 \%$ when SLNB was performed after NAC (11-16). Rates of identification in the NSABP B-27 study and the French GANEA study were 85 and $90 \%$, respectively (13-17). In the present study, the rate of identification of SLN was similar to previous reports, indicating that the identification of SLN in patients following NAC is similar to that in patients who have not received NAC.

As for whether SLNB after chemotherapy is able to eliminate the requirement for two surgical procedures, a more comprehensive assessment of the ability of pre-operative chemotherapy to achieve a complete pathological response is required. The down-staging effect of preoperative chemotherapy and may reduce the number of patients that require axillary lymph node dissection. Finally, it does not delay the administration of preoperative chemotherapy (18). In the present study, all SLNs were analysed by OSNA. The advantage of OSNA over other conventional methods is that it can semi-quantitatively evaluate the total tumoral load (TTL) in the SLNs when the whole nodes are examined. In the present study, patients with OSNA-positive SLNs (ITC as well as micro- and macrometastases) were subject to axillary lymph-node dissection. Only two cases with macrometastases (TTL SLNB: $2.7 \times 10^{4}$ and $2.1 \times 10^{6}$ copies $/ \mu$ l) showed an additional positive lymph node on axillary lymphadenectomy. Of note, none of the patients diagnosed with ITC and micrometastases showed any evidence of other metastases after axillary lymphadenectomy, suggesting that axillary dissection may not be necessary for patients whose TTL is low. Previous studies have shown that the TTL is useful for assessing SLNs and avoiding unnecessary surgical procedures (19-22).

One limitation of the present study is that the number of patients examined was not sufficient for firm conclusions to be drawn. However, the results remain meaningful, as the accuracy and sensitivity of OSNA in SLN analysis were demonstrated. Furthermore, the TTL, assessed by the OSNA assay, may assist with predicting the likelihood of further axillary metastases. The OSNA assay is automatized and assessed intraoperatively, and the TTL is reproducible and not correlated with the type of surgery, the histological tumour subtype or NAC.

In conclusion, the present study demonstrated that whole SLN analysis by OSNA is a highly specific, sensitive and reproducible diagnostic method for node-negative breast cancer patients after NAC and that the TTL may assist with predicting additional non-SLN metastases. However, further prospective studies using larger patients cohorts are required to fully establish a novel nomogram, including the results of the OSNA assay.

\section{References}

1. Lyman GH, Temin S, Edge SB, Newman LA, Turner RR, Weaver DL, Benson AB III, Bosserman LD, Burstein HJ, Cody H III, et al: Sentinel lymph node biopsy for patients with early-stage breast cancer: American society of clinical oncology clinical practice guideline update. J Clin Oncol 32: 1365-1383, 2014.
2. El Saghir NS, Eniu A, Carlson RW, Aziz Z, Vorobiof D and Hortobagyi GN; Breast Health Global Initiative Systemic Therapy Focus Group: Locally advanced breast cancer: Treatment guideline implementation with particular attention to low- and middle-income countries. Cancer 113 (Suppl 8): S2315-S2324, 2008.

3. Bonadonna G, Veronesi U, Brambilla C, Ferrari L, Luini A, Greco M, Bartoli C, Coopmans de Yoldi G, Zucali R, Rilke F, et al: Primary chemotherapy to avoid mastectomy in tumors with diameters of three centimeters or more. J Natl Cancer Inst 82: $1539-1545,1990$

4. Loibl S, von Minckwitz G, Raab G, Blohmer JU, Dan Costa S, Gerber B, Eidtmann H, Petrich S, Hilfrich J, Jackisch C, et al: Surgical procedures after neoadjuvant chemotherapy in operable breast cancer: Results of the GEPARDUO trial. Ann Surg Oncol 13: 1434-1442, 2006.

5. Edge SB, Byrd DR, Compton CC, Fritz AG, Greene FL and Trotti A (eds). AJCC cancer staging manual. $7^{\text {th }}$ edition. Springer, New York, 2010.

6. Tsujimoto M, Nakabayashi K, Yoshidome K, Kaneko T, Iwase T, Akiyama F, Kato Y, Tsuda H, Ueda S, Sato K, et al: One-step nucleic acid amplification for intraoperative detection of lymph node metastasis in breast cancer patients. Clin Cancer Res 13: 4807-4816, 2007.

7. Mansel RE, Fallowfield L, Kissin M, Goyal A, Newcombe RG, Dixon JM, Yiangou C, Horgan K, Bundred N, Monypenny I, et al: Randomized multicenter trial of sentinel node biopsy versus standard axillary treatment in operable breast cancer: The ALMANAC Trial. J Natl Cancer Inst 98: 599-609, 2006.

8. Purushotham AD, Upponi S, Klevesath MB, Bobrow L, Millar K, Myles JP and Duffy SW: Morbidity after sentinel lymph node biopsy in primary breast cancer: Results from a randomized controlled trial. J Clin Oncol 23: 4312-4321, 2005.

9. Bleiweiss IJ: Sentinel lymph nodes in breast cancer after 10 years: Rethinking basic principles. Lancet Oncol 7: 686-692, 2007.

10. Benson JR and Jatoi I: Sentinel lymph node biopsy and neoadjuvant chemotherapy in breast cancer patients. Future Oncol 10: 577-586, 2014.

11. Fisher B, Brown A, Mamounas E, Wieand S, Robidoux A, Margolese RG, Cruz AB Jr, Fisher ER, Wickerham DL, Wolmark $\mathrm{N}$, et al: Effect of preoperative chemotherapy on local-regional disease in women with operable breast cancer: Findings from national surgical adjuvant breast and bowel project B-18. J Clin Oncol 15: 2483-2493, 1997.

12. Gianni L, Baselga J, Eiermann W, Porta VG, Semiglazov V, Lluch A, et al: First report of the European Cooperative Trial in operable breast cancer: effects of primary systemic therapy on local-regional disease. Proc Am Soc Clin Oncol 21: 34a, 2002.

13. Mamounas EP, Brown A, Anderson S, Smith R, Julian T, Miller B, Bear HD, Caldwell CB, Walker AP, Mikkelson WM, et al: Sentinel node biopsy after neoadjuvant chemotherapy in breast cancer: Results from national surgical adjuvant breast and bowel project protocol B-27. J Clin Oncol 23: 2694-2702, 2005.

14. Nason KS, Anderson BO, Byrd DR, Dunnwald LK, Eary JF, Mankoff DA, Livingston R, Schmidt RA, Jewell KD, Yeung RS and Moe RE: Increased false negative sentinel node biopsy rates after preoperative chemotherapy for invasive breast cancer. Cancer 89: 2187-2194, 2000.

15. Tafra L, Verbanac KM and Lannin DR: Preoperative chemotherapy and sentinel lymphadenectomy for breast cancer. Am J Surg 182: 312-315, 2001.

16. Hino M, Sano M, Sato N and Homma K: Sentinel lymph node biopsy after neoadjuvant chemotherapy in a patient with operable breast cancer. Surg Today 38: 585-591, 2008.

17. Classe JM, Bordes V, Campion L, Mignotte H, Dravet F, Leveque J, Sagan C, Dupre PF, Body G and Giard S: Sentinel lymph node biopsy after neoadjuvant chemotherapy for advanced breast cancer: Results of Ganglion Sentinelle et Chimiotherapie Neoadjuvante, a French prospective multicenter study. J Clin Oncol 27: 726-732, 2009.

18. Buchholz TA, Lehman CD, Harris JR, Pockaj BA, Khouri N, Hylton NF, Miller MJ, Whelan T, Pierce LJ, Esserman LJ, et al: Statement of the science concerning locoregional treatments after preoperative chemotherapy for breast cancer: A national cancer institute conference. J Clin Oncol 26: 791-797, 2008.

19. Ohi Y, Umekita Y, Sagara Y, Rai Y, Yotsumoto D, Matsukata A, Baba S, Tamada S, Matsuyama Y, Ando M, et al: Whole sentinel lymph node analysis by a molecular assay predicts axillary node status in breast cancer. Br J Cancer 107: 1239-1243, 2012. 
20. Peg V, Espinosa-Bravo M, Vieites B, Vilardell F, Antúnez JR, de Salas MS, Delgado-Sánchez JJ, Pinto W, Gozalbo F, Petit A, et al: Intraoperative molecular analysis of total tumor load in sentinel lymph node: A new predictor of axillary status in early breast cancer patients. Breast Cancer Res Treat 139: 87-93, 2013

21. Rubio IT, Espinosa-Bravo M, Rodrigo M, Amparo Viguri Diaz M, Hardisson D, Sagasta A, Dueñas B and Peg V: Nomogram including the total tumoral load in the sentinel nodes assessed by one-step nucleic acid amplification as a new factor for predicting nonsentinel lymph node metastasis in breast cancer patients. Breast Cancer Res Treat 147: 371-380, 2014.
22. Espinosa-Bravo M, Sansano I, Pérez-Hoyos S, Ramos M, Sancho M, Xercavins J, Rubio IT and Peg V: Prediction of non-sentinel lymph node metastasis in early breast cancer by assessing total tumoral load in the sentinel lymph node by molecular assay. Eur J Surg Oncol 39: 766-773, 2013. 